\title{
Total antioxidant capacity is associated with mortality of patients with severe traumatic brain injury
}

Leonardo Lorente ${ }^{1 *}$, María M. Martín², Teresa Almeida ${ }^{3}$, Pedro Abreu-González ${ }^{4}$, Luis Ramos ${ }^{5}$, Mónica Argueso $^{6}$, Marta Riaño-Ruiz ${ }^{7}$, Jordi Solé-Violán ${ }^{8}$ and Alejandro Jiménez ${ }^{9}$

\begin{abstract}
Background: Previously, circulating total antioxidant capacity (TAC) in traumatic brain injury (TBI) patients has been scarcely studied and only in studies of small sample size (lower than $55 \mathrm{TBI}$ patients). In one study were found higher serum TAC in non-survivor than in survivor TBI patients; however, an association between circulating TAC and mortality in patients with TBI has not been previously reported. Thus, the objective of this study was to determine whether there is an association between circulating TAC, peroxidation state and mortality in patients with severe TBI.
\end{abstract}

Methods: This was a multicenter, observational and prospective study was carried out in six Spanish Intensive Care Units. We included patients with severe TBI defined as Glasgow Coma Scale (GCS) lower than 9. We excluded patients with Injury Severity Score (ISS) in non-cranial aspects higher than 9. We measured serum TAC on day 1 of TBI. The 30-day mortality was established as endpoint.

Results: Non-surviving TBI patients $(N=27)$ showed higher serum TAC $(P<0.001)$ than survivor ones $(N=73)$. Logistic regression analyses showed that serum TAC higher than $2.59 \mathrm{nmol} / \mathrm{mL}$ were associated with 30 -day mortality controlling for APACHE-II and CT classification (OR=4.40; $95 \% \mathrm{Cl}=1.14-16.98 ; P=0.03)$, controlling for GCS and age $(\mathrm{OR}=5.88 ; 95 \% \mathrm{Cl}=1.57-22.06 ; P=0.009)$, and controlling for CT classification and admission abnormal pupils $(\mathrm{OR}=3.89 ; 95 \% \mathrm{Cl}=1.30-11.61 ; P=0.02)$. There was an association between serum TAC and malondialdehyde (a biomarker of lipid peroxidation) levels (rho $=0.25 ; p=0.01$ ), APACHE-II score (rho $=0.23 ; p=0.03$ ) and GCS (rho $=-0.21 ; p=0.04$ ).

Conclusions: To our knowledge, our series is the largest reporting data on circulating TAC in patients with severe TBI. The most relevant and new findings of our study were that there is an association between circulating TAC and peroxidation state and mortality in patients with severe TBI.

Keywords: Total antioxidant capacity, Brain trauma, Patients, Mortality, Injury

\section{Background}

Traumatic brain injury (TBI) could leads to death, disability, and high resources consume [1]. TBI causes two kinds of injury in the brain: 1) Primary injury, which appears at moment of the impact and is due to the initial physical forces applied to brain; 2) Secondary injury, which appears

\footnotetext{
* Correspondence: lorentemartin@msn.com

${ }^{1}$ Intensive Care Unit, Hospital Universitario de Canarias, Ofra, s/n. La Laguna, 38320 Santa Cruz de Tenerife, Spain

Full list of author information is available at the end of the article
}

in the following hours or days, and leads to neuroinflammatory response and free radical generation [2].

Reactive oxygen species (ROS) are produced after TBI and they are involved in the secondary brain injury [3-6]. Under physiologic conditions, ROS are carefully balanced by the action of antioxidant defenses in cerebral tissue. These antioxidants do not work alone but they establish complex interactions with each others [7]. Thus, measurement of total antioxidant capacity (TAC) in serum or plasma, may give more biologically relevant information about patient antioxidant status than that obtained from

\section{() BioMed Central}

(c) 2015 Lorente et al. This is an Open Access article distributed under the terms of the Creative Commons Attribution License (http://creativecommons.org/licenses/by/4.0), which permits unrestricted use, distribution, and reproduction in any medium, provided the original work is properly credited. The Creative Commons Public Domain Dedication waiver (http:// creativecommons.org/publicdomain/zero/1.0/) applies to the data made available in this article, unless otherwise stated. 
measuring concentrations of individual compounds [8]. However, when antioxidant defenses are overwhelmed, oxidative stress results, which can cause significant damage to lipids, proteins, carbohydrates and nucleic acids [9].

Previously, there was found that non-survivor TBI patient showed higher lipid peroxidation than survivor patients [10-13]; however, there was also found the absence of that association [14]. In addition, circulating TAC in TBI patients has been scarcely studied and only in studies of small sample size (lower than 55 TBI patients) [15-17]. In one study were found higher serum TAC in non-survivor than in survivor TBI patients [15]; however, an association between circulating TAC and mortality in patients with TBI has not been previously reported. Thus, the objective of this study was to determine whether there is an association between circulating TAC, peroxidation state and mortality in patients with severe TBI.

\section{Methods}

\section{Design and subjects}

A prospective, observational, multicenter study was carried out between 2009-2012 in six Spanish Intensive Care Units. The study was approved by the Institutional Review Board of the 6 participating hospitals: Hospital Universitario de Canarias (La Laguna), Hospital Universitario Nuestra Señora de Candelaria (Santa Cruz de Tenerife), Hospital Clínico Universitario de Valencia (Valencia), Hospital General de La Palma (La Palma), Hospital Universitario Dr. Negrín (Las Palmas de Gran Canaria), Hospital Insular (Las Palmas de Gran Canaria). Written informed consent from the legal guardians of the patients was obtained.

The patient cohort, including 100 patients with severe TBI, is the same that was used in a previous publication by our team [13]. Previously we determined malondialdehyde (MDA) to assess lipid peroxidation, and at current study we have analyzed TAC.

We included patients with severe TBI defined as Glasgow Coma Scale (GCS) lower than 9 points [18]. We excluded patients with age less than 18 years, pregnancy, inflammatory or malignant disease and Injury Severity Score (ISS) in non-cranial aspects higher than 9 points [19].

\section{Variables recorded}

The following variables were recorded for each patient at hospital admission: sex, age, brain lesion according to the Marshall computer tomography (CT) classification [20], ISS, GCS, lactic acid, platelets, international normalized ratio (INR), activated partial thromboplastin time (aPTT), fibrinogen, and Acute Physiology and Chronic Health Evaluation II (APACHE II) score [21].

\section{End-point}

The 30-day mortality was established as endpoint.

\section{Blood sample collection}

Blood samples were collected on day 1 of TBI in tubes with separator gel. After coagulation during $10 \mathrm{~min}$ at room temperature, serum was obtained by centrifugation at $1000 \mathrm{~g}$ for $15 \mathrm{~min}$. The samples were aliquoted and frozen at $-80{ }^{\circ} \mathrm{C}$ until determination.

\section{Serum TAC analysis}

TAC in serum samples was evaluated using antioxidant assay kit (Cayman Chemical Corporation, Ann Arbor, USA). The assay relies on the ability of antioxidants in the sample to inhibit the oxidation of $\operatorname{ABTS}^{\oplus}\left(2,2^{\prime}\right.$-azinodi-[3-ethylbenzthiazoline sulphonate]) to $\mathrm{ABTS}^{{ }^{+}}$by metmyoglobin. The capacity of the antioxidants in the sample to prevent ABTS oxidation, is compared with that of Trolox, a water-soluble tocopherol analogue, and is quantified as molar Trolox equivalents. All samples were assayed in duplicate at 20 -fold dilutions in assay buffer following manufacturer's instructions. Absorbance at $750 \mathrm{~nm}$ was measured using the EnSpire multimode plate reader (PerkinElmer,Waltham, MA, USA). The serum concentration of TAC was expressed in mmol/L. The detection limit of this assay was $0.04 \mathrm{mmol} / \mathrm{L}$; the intra- and inter-assay CV were $3.4 \%$ and $3.0 \%$, respectively. To avoid the possible dispersion of serum TAC results, all the samples were processed at the same time, at the end of the recruitment process. Serum TAC determination was performed by a laboratory technician blinded to all clinical data. TAC assay was performed in the Genetic Unit of the Instituto de Enfermedades Tropicales y Salud Pública de Canarias of the University of the La Laguna (Tenerife, Spain).

\section{Serum MDA analysis}

Malondialdehyde (MDA) is an end-product formed during this lipid peroxidation, due to degradation of cellular membrane phospholipids. MDA is released into extracellular space and finally into the blood; and has been used as an effective biomarker of lipid oxidation [22, 23].

Serum MDA levels were measured using thiobarbituric acid-reactive substance (TBARS) method as described by Kikugawa et al. [24]. The pink complex of samples was extracted in n-butanol. Each sample was placed in a 96-well plate and read at $535 \mathrm{~nm}$ in a microplate spectrophotometer reader (Benchmark Plus, Bio-Rad, Hercules, CA, USA). The detection limit of this assay was $0.079 \mathrm{nmol} / \mathrm{ml}$; the intra- and inter-assay $\mathrm{CV}$ were $1.82 \%$ and $4.01 \%$, respectively. The serum concentration of MDA was expressed in $\mathrm{nmol} / \mathrm{ml}$. To avoid the possible dispersion of serum MDA level results, all the samples were processed at the same time, at the end of the recruitment process. 
MDA determination was performed by a laboratory technician blinded to all clinical data. The assay of MDA levels was centralized in the Department of Physiology, Faculty of Medicine (University of the La Laguna. Santa Cruz de Tenerife. Spain).

\section{Statistical methods}

Categorical variables are reported as frequencies and percentages; and comparisons between groups were carried out with chi-square test. Continuous variables are reported as medians and interquartile ranges; and comparisons between groups were carried out using WilcoxonMann-Whitney test.

Receiver operating characteristic (ROC) analysis was carried out to determine the goodness-of-fit of serum TAC to predict 30-day mortality. Kaplan-Meier analysis of survival at 30 days and comparisons by log-rank test were carried out using serum TAC lower/higher than

Table 1 Comparison between survivor and non-survivor TBI patients

\begin{tabular}{|c|c|c|c|}
\hline & $\begin{array}{l}\text { Non-survivors } \\
(n=27)\end{array}$ & $\begin{array}{l}\text { Survivors } \\
(n=73)\end{array}$ & $\begin{array}{l}\text { P- } \\
\text { value }\end{array}$ \\
\hline Sex female - n (\%) & $11(40.7)$ & $12(16.4)$ & 0.02 \\
\hline Admission abnormal pupils - n (\%) & $12(44.4)$ & $11(15.1)$ & 0.003 \\
\hline Marshall CT classification - n (\%) & & & 0.002 \\
\hline Non-evacuated mass lesion & $8(29.6)$ & $3(4.1)$ & \\
\hline Evacuated mass lesion & $5(18.5)$ & $26(35.6)$ & \\
\hline Type 4 injury & $6(22.2)$ & $10(13.7)$ & \\
\hline Type 3 injury & $5(18.5)$ & $13(17.8)$ & \\
\hline Type 2 injury & $3(11.1)$ & $21(28.8)$ & \\
\hline Type 1 injury & 0 & 0 & \\
\hline CT with high risk of death (types $3,4,6)-\mathrm{n}(\%)$ & $19(70.4)$ & $26(35.6 \%)$ & 0.003 \\
\hline Age (years) - median (p 25-75) & $66(45-76)$ & $47(32-67)$ & $<0.001$ \\
\hline Temperature $\left({ }^{\circ} \mathrm{C}\right)$ - median ( $\mathrm{p}$ 25-75) & $36.0(35.0-37.0)$ & 37. (35.6-37.3) & 0.12 \\
\hline Sodium (mEq/L) - median (p 25-75) & $141(135-149)$ & $139(138-142)$ & 0.19 \\
\hline Glycemia (g/dL) - median (p 25-75) & $161(142-189)$ & $139(120-163)$ & 0.08 \\
\hline Leukocytes $* 10^{3} / \mathrm{mm}^{3}-$ median ( $\left.\mathrm{p} 25-75\right)$ & $18.3(10.7-23.9)$ & $14.7(10.2-19.3)$ & 0.46 \\
\hline $\mathrm{PaO} 2(\mathrm{mmHg})$ - median ( $\mathrm{p}$ 25-75) & $141(104-186)$ & $151(116-217)$ & 0.34 \\
\hline $\mathrm{PaO} 2 / \mathrm{FIO}_{2}$ ratio - median (p 25-75) & $190(154-316)$ & $336(242-407)$ & 0.11 \\
\hline Bilirubin (mg/dl) - median (p 25-75) & $0.75(0.53-1.05)$ & $0.50(0.40-0.87)$ & 0.045 \\
\hline Creatinine (mg/dl) - median ( $\mathrm{p} 25-75)$ & $0.95(0.70-1.10)$ & $0.80(0.70-0.90)$ & 0.44 \\
\hline Hemoglobin (g/dL) - median ( $\mathrm{p} 25-75)$ & $11.1(9.4-12.3)$ & $11.4(10.4-13.0)$ & 0.87 \\
\hline Glasgow Coma Scale score - median ( $p$ 25-75) & $3(3-6)$ & $7(6-8)$ & $<0.001$ \\
\hline Lactic acid (mmol/L) - median (p 25-75) & $1.90(1.15-4.55)$ & $1.70(1.23-2.50)$ & 0.16 \\
\hline Platelets $* 10^{3} / \mathrm{mm}^{3}-$ median (p 25-75) & $215(139-264)$ & $182(143-252)$ & 0.48 \\
\hline International normalized ratio - median (p 25-75) & $1.22(1.01-1.67)$ & $1.03(0.92-1.15)$ & 0.15 \\
\hline aPTT (seconds) - median (p 25-75) & $26(25-31)$ & $28(25-32)$ & 0.86 \\
\hline Fibrinogen (mg/dl) - median ( $\mathrm{p}$ 25-75) & $376(246-560)$ & $350(282-444)$ & 0.32 \\
\hline APACHE-II score - median (p 25-75) & $26(25-32)$ & $19(17-23)$ & $<0.001$ \\
\hline Injury Severity Score - median (p 25-75) & $25(25-27)$ & $25(25-32)$ & 0.24 \\
\hline Intracranial pressure $(\mathrm{mmHg})$ - median (p 25-75) & $20(12-30)$ & $15(14-20)$ & 0.27 \\
\hline Cerebral perfusion pressure $(\mathrm{mmHg})$ - median ( $\mathrm{p}$ 25-75) & $60(54-69)$ & $68(57-70)$ & 0.46 \\
\hline Malondialdehyde $(\mathrm{nmol} / \mathrm{mL}$ ) - median (p 25-75) & $1.99(1.31-2.76)$ & $1.35(1.02-1.79)$ & $<0.001$ \\
\hline Total antioxidant capacity (nmol/mL) - median (p 25-75) & $5.09(2.78-9.95)$ & $2.31(1.85-2.84)$ & $<0.001$ \\
\hline
\end{tabular}

$\mathrm{CT}$ Computer tomography, $\mathrm{p}$ percentile, $\mathrm{PaO}_{2}$ pressure of arterial oxygen, $\mathrm{FIO}_{2}$ fraction inspired oxygen, aPTT activated partial thromboplastin time, APACHE II Acute Physiology and Chronic Health Evaluation * multiplied by 
$2.59 \mathrm{nmol} / \mathrm{mL}$ as the independent variable and survival at 30 days as the dependent variable.

Multiple binomial logistic regression analyses were carried out to determine the association between serum TAC and 30-day mortality. We constructed three multiple binomial logistic regression models with only three predictor variables in each model, due to that the number of events (death) was 27, to avoid a final model of order slightly higher than required due to an over fitting effect. In the first model were included $\mathrm{CT}$ with high risk of death (types 3,4,6), APACHE-II score and serum $\mathrm{TAC}>2.59 \mathrm{nmol} / \mathrm{mL}$. In the second model were included age, GCS and serum TAC $>2.59 \mathrm{nmol} / \mathrm{mL}$. In the third model were included $\mathrm{CT}$ with high risk of death (types 3,4,6), admission abnormal pupils and serum TAC $>2.59 \mathrm{nmol} / \mathrm{mL}$. Odds Ratio and $95 \%$ confidence intervals were calculated as measurement of the clinical impact of the predictor variables. We calculated for each multiple binomial logistic regression analysis, the overall predictive capacity to predict 30-day mortality and its predictive capacity for 30-day mortality (including area under curve, sensitivity, specificity, positive likelihood ratio, negative likelihood ratio, positive predicted value, negative predicted value).

A $P$ value of less than 0.05 was considered statistically significant. Statistical analyses were performed with SPSS 17.0 (SPSS Inc., Chicago, IL, USA) and NCSS 2000 (Kaysville, Utah) and LogXact 4.1, (Cytel Co., Cambridge, MA).

\section{Results}

Comparisons between surviving $(N=73)$ and nonsurviving $(N=27)$ patients are shown in Table 1. Non-surviving TBI patients showed higher rate of female $(p=0.02)$. There were statistically significant differences in CT classification between non-surviving and surviving patients $(p=0.002)$. Non-surviving TBI patients showed lower GCS $(p<0.001)$, and higher age $(p<0.001)$ and APACHE-II score $(p<0.001)$ than survivor ones. In addition, non-surviving patients showed higher serum TAC $(p<0.001)$ and MDA $(p<0.001)$ levels than surviving ones.

The area under the curve (AUC) for serum TAC as predictor of 30-day mortality was $0.83(95 \% \mathrm{CI}=0.74-0.90$; $P<0.001$ ) (Fig. 1).

Proportions of non-survivors was higher in patients with serum TAC higher than $2.59 \mathrm{nmol} / \mathrm{mL}$ (21of $48 ; 43.8 \%$ ) compared with those with lower serum TAC (6 of 52; $11.5 \%)$. For this comparison power analysis was higher than $95 \%$.

Survival analysis showed that patients with serum TAC higher than $2.59 \mathrm{nmol} / \mathrm{mL}$ presented higher 30-day mortality than patients with lower levels (Hazard ratio $=4.6$; $95 \% \mathrm{CI}=2.13-9.76 ; P<0.001$ ) (Fig. 2 ).

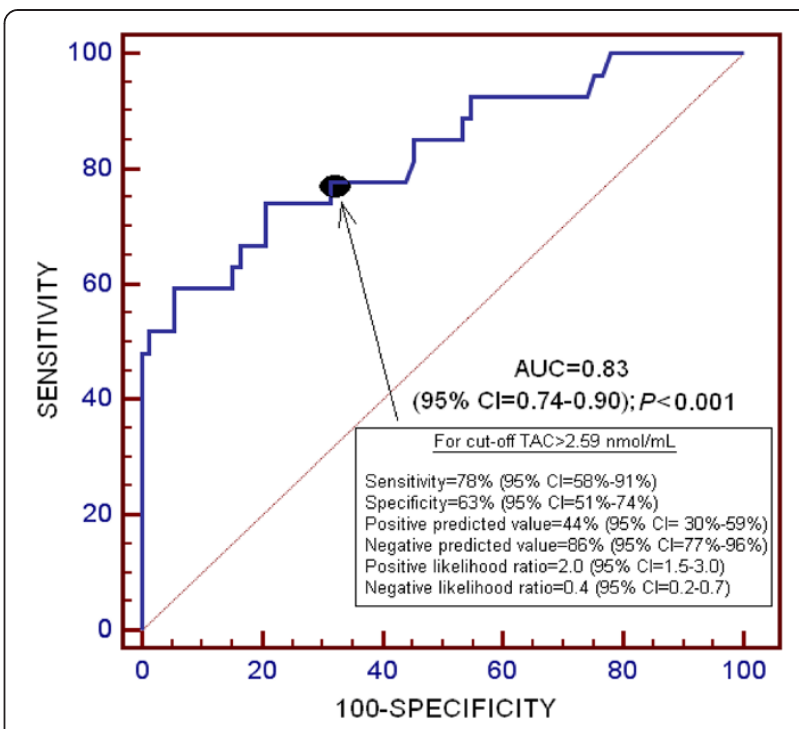

Fig. 1 Receiver operation characteristic analysis using serum total antioxidant capacity (TAC) as predictor of mortality at 30 days

Multiple binomial logistic regression analysis showed that serum TAC higher than $2.59 \mathrm{nmol} / \mathrm{mL}$ were associated with 30-day mortality controlling for APACHE-II and $\mathrm{CT}$ classification $(\mathrm{OR}=4.40 ; 95 \% \mathrm{CI}=1.14-16.98$; $P=0.03)$, controlling for GCS and age ( $\mathrm{OR}=5.88 ; 95 \%$ $\mathrm{CI}=1.57-22.06 ; P=0.009)$, and controlling for CT classification and admission abnormal pupils $(\mathrm{OR}=3.89$; $95 \% \mathrm{CI}=1.30-11.61 ; P=0.02$ ) (Table 2). The overall predictive capacity for the first, second and third multiple binomial logistic regression analyses to predict 30-day mortality was $85.4 \%, 82.3 \%$ and $76.0 \%$, respectively. The area under curve for the first, second and third multiple binomial logistic regression analyses to predict 30-day mortality was $0.79,0.74$ and 0.59 , respectively (Table 3 ).

There was an association between serum TAC and MDA levels (rho $=0.25 ; p=0.01$ ), APACHE-II score $($ rho $=0.23 ; p=0.03)$ and GCS $($ rho $=-0.21 ; p=0.04)$.

\section{Discussion}

To our knowledge, our series is the largest reporting data on circulating TAC in patients with severe TBI. The most relevant and new findings of our study were that there is an association between circulating TAC and peroxidation state and mortality in patients with severe TBI.

We found that non-survivor TBI patients showed higher serum TAC than survivor ones. These findings are in consonance with those of other previous study of small sample size [15]. In addition, these findings are consistent with the results of other studies in septic patients showing higher circulating TAC in non-survivor septic patients than in survivor ones [25-27]. A new aspect of our study was the association between serum TAC and mortality in severe TBI patients according to 


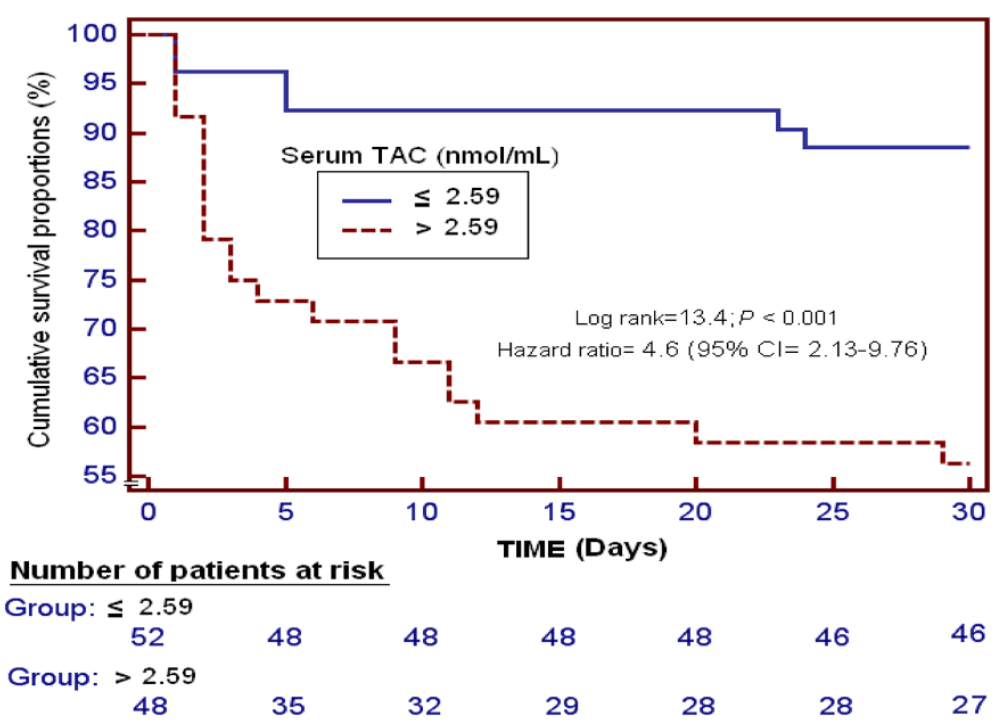

Fig. 2 Survival curve at 30 days using $2.59 \mathrm{nmol} / \mathrm{mL}$ of serum total antioxidant capacity (TAC) as cut-off

the results of regression analysis. That finding is also in consonance with the results of other study in septic patients showing that serum TAC is associated with mortality in severe septic patients [27]. Besides, we report for the first time that serum TAC could be used to predict mortality in patients with severe TBI according the results of ROC curve analysis.

We found a higher rate of death in female than in male. Previously, there was found a influence of the sex in the death rate $[28,29]$. However, there was found a worse outcome in females [28], and in males [29]. And

Table 2 Multiple binomial logistic regression analysis to predict 30-day mortality

\begin{tabular}{|c|c|c|c|}
\hline Variable & $\begin{array}{l}\text { Odds } \\
\text { ratio }\end{array}$ & $\begin{array}{l}95 \% \text { confidence } \\
\text { interval }\end{array}$ & $P$ \\
\hline \multicolumn{4}{|l|}{ First model } \\
\hline $\begin{array}{l}C T \text { with high risk of death } \\
\text { (types } 3,4,6 \text { ) }\end{array}$ & 5.22 & $1.264-21.555$ & 0.02 \\
\hline APACHE-II score & 1.14 & $1.206-1.655$ & $<0.001$ \\
\hline Serum TAC $>2.59 \mathrm{nmol} / \mathrm{mL}$ & 4.40 & $1.142-16.977$ & 0.03 \\
\hline \multicolumn{4}{|l|}{ Second model } \\
\hline Age & 1.08 & $1.033-1.118$ & $<0.001$ \\
\hline GCS score & 0.54 & $0.386-0.752$ & $<0.001$ \\
\hline Serum TAC $>2.59 \mathrm{nmol} / \mathrm{mL}$ & 5.88 & $1.565-22.064$ & 0.009 \\
\hline \multicolumn{4}{|l|}{ Third model } \\
\hline $\begin{array}{l}C T \text { with high risk of death } \\
\text { (types } 3,4,6 \text { ) }\end{array}$ & 3.84 & $1.317-11.202$ & 0.01 \\
\hline Admission abnormal pupils & 4.06 & $1.311-12.596$ & 0.02 \\
\hline Serum TAC > $2.59 \mathrm{nmol} / \mathrm{mL}$ & 3.89 & $1.301-11.607$ & 0.02 \\
\hline
\end{tabular}

CT Computer tomography, APACHE II Acute Physiology and Chronic Health Evaluation, TAC Total antioxidant capacity, GCS Glasgow Coma Scale the influence of the hormones was pointed as the possible explanation for those findings in both cases; thus the influence and the cause of sex in TBI outcome remains unclear.

Another interesting finding of our study was the association between serum TAC and TBI severity, assessed by GCS. That finding is in consonance with that of other previous study of small sample size [16].

We found that non-survivor TBI patients showed higher serum MDA levels (as biomarker of lipid peroxidation) than survivor ones. That finding is in consonance with the results of other studies showing that nonsurvivor TBI patient had higher lipid peroxidation than survivor patients [10-13]; however, in other series was not found that association [14].

Table 3 Predictive capacity of the three multiple binomial logistic regression analysis to predict 30-day mortality

\begin{tabular}{|c|c|c|c|}
\hline & First model & Second model & Third model \\
\hline $\begin{array}{l}\text { Overall predictive } \\
\text { capacity }\end{array}$ & $85.4 \%$ & $82.3 \%$ & $76.0 \%$ \\
\hline $\begin{array}{l}\text { Area under curve; } \\
\text { p-value }\end{array}$ & $0.79 ; p<0.001$ & $0.74 ; p<0.001$ & $0.59 ; p=0.03$ \\
\hline Sensitivity (95 \% Cl) & $64(43-82)$ & $56(35-76)$ & $22(9-42)$ \\
\hline Specificity (95 \% Cl) & $93(84-98)$ & $92(83-97)$ & 96 (89-99) \\
\hline $\begin{array}{l}\text { Positive likelihood } \\
\text { ratio }(95 \% \mathrm{Cl})\end{array}$ & $9.1(3.7-22.2)$ & $6.6(2.9-15.4)$ & $5.4(1.5-20.1)$ \\
\hline $\begin{array}{l}\text { Negative likelihood } \\
\text { ratio }(95 \% \text { Cl) }\end{array}$ & $0.4(0.2-0.7)$ & $0.5(0.3-0.8)$ & $0.8(0.7-1.0)$ \\
\hline $\begin{array}{l}\text { Positive predicted } \\
\text { value }(95 \% \mathrm{Cl})\end{array}$ & 76 (53-92) & $70(46-88)$ & 67 (30-93) \\
\hline $\begin{array}{l}\text { Negative predicted } \\
\text { value }(95 \% \mathrm{Cl})\end{array}$ & $88(78-94)$ & $86(76-93)$ & $77(67-85)$ \\
\hline
\end{tabular}

Cl confidence interval 
In addition, other novel aspect of our study was that there was a positive association between serum TAC and lipid peroxidation, assessed by serum MDA levels, in severe TBI patients.

We believe that all these findings might suggest that non-surviving TBI patients with respect to survivor ones have an increased production of ROS and the increased TAC attempts to compensate the high production of oxidant products to maintain the balance between oxidant and antioxidant state; however, in non-surviving TBI patients this increased TAC is not enough to compensate the high production of oxidants species and finally present a high ROS production and high peroxidation of lipids, proteins, carbohydrates and nucleic acids. From a therapeutic perspective, the use of antioxidant agents could be used as a new class of drugs for the treatment of patients with severe TBI according the results of animal models [30-34].

Finally, some limitations of our study should be recognized. First, the measure of other compounds of oxidant and antioxidant states would be desirable in order to better evaluate this balance. Second, we did not perform the analysis of serum TAC during follow-up. Third, we did not report data on many patients were excluded from the study and the motivation for missing. Fourth, blood samples for serum TAC were collected on the day of TBI; however, the timing of the blood sampling may be different among patients due to that the exact moment of the blood sampling was not reported. Thus, additional studies are needed to confirm the finding of our study.

\section{Conclusions}

To our knowledge, our series is the largest reporting data on circulating TAC in patients with severe TBI. The most relevant and new findings of our study were that there is an association between circulating TAC and peroxidation state and mortality in patients with severe TBI.

\begin{abstract}
Abbreviations
TBI: Traumatic brain injury; TAC: Total antioxidant capacity; GCS: Glasgow Coma Scale; ISS: Injury Severity Score; $\mathrm{PaO}_{2}$ : Pressure of arterial oxygen; $\mathrm{FIO}_{2}$ : Fraction inspired oxygen; aPTT: activated partial thromboplastin time; APACHE II: Acute Physiology and Chronic Health Evaluation.
\end{abstract}

\section{Competing interests}

The authors declare that they have no competing interests.

\section{Authors' contributions}

Conceived and designed the experiments: LL. Acquired the data: LL, MMM, TA, PAG, LR, MA, MRR, JSV. Serum TAC analysis: TA. Serum MDA analysis: PAG. Analized the data: LL, AJ. Wrote the paper: LL, TA. All authors revised the manuscript critically for important intellectual content and made the final approval of the version to be published.

\section{Acknowledgments}

We would like to thank Andreína León Carmenatis and Henoc del Rosario García for their technical assistance. This study was supported by fundings from Fundación Canaria de Investigación Sanitaria (FUNCANIS) (La Laguna,
Tenerife, Spain). The fundings have not affected in study design; in the collection, analysis, and interpretation of data; in the writing of the manuscript; and in the decision to submit the manuscript for publication.

\section{Author details}

'Intensive Care Unit, Hospital Universitario de Canarias, Ofra, s/n. La Laguna, 38320 Santa Cruz de Tenerife, Spain. ${ }^{2}$ Intensive Care Unit, Hospital Universitario Nuestra Señora de Candelaria, Crta del Rosario s/n, Santa Cruz de Tenerife 38010, Spain. ${ }^{3}$ Unidad de Genética. Instituto de Enfermedades Tropicales y Salud Pública de Canarias, Universidad de La Laguna, Campus de Anchieta, Avda. Astrofísico Francisco Sánchez s/n, La Laguna, Tenerife 38071, Spain. ${ }^{4}$ Deparment of Phisiology. Faculty of Medicine, University of the La Laguna, Santa Cruz de Tenerife, Spain. ${ }^{5}$ Intensive Care Unit, Hospital General La Palma, Buenavista de Arriba s/n, Breña Alta, La Palma 38713, Spain. ${ }^{6}$ Intensive Care Unit, Hospital Clínico Universitario de Valencia, Avda. Blasco Ibáñez n¹7-19, Valencia 46004, Spain. Servicio de Bioquímica Clínica, Complejo Hospitalario Universitario Insular Materno-Infantil, Plaza Dr. Pasteur s/n, Las Palmas de Gran Canaria 35016, Spain. ${ }^{8}$ Intensive Care Unit, Hospital Universitario Dr. Negrín, CIBERES, Barranco de la Ballena s/n, Las Palmas de Gran Canaria 35010, Spain. ${ }^{9}$ Research Unit, Hospital Universitario de Canarias, Ofra, s/n. La Laguna, 38320 Santa Cruz de Tenerife, Spain.

Received: 21 February 2015 Accepted: 13 July 2015

Published online: 25 July 2015

\section{References}

1. Brain Trauma Foundation; American Association of Neurological Surgeons; Congress of Neurological Surgeons. Guidelines for the management of severe traumatic brain injury. J Neurotrauma. 2007;24:51-106.

2. Maldonado MD, Murillo-Cabezas F, Terron MP, Flores LJ, Tan DX, Manchester LC, et al. The potential of melatonin in reducing morbiditymortality after craniocerebral trauma. J Pineal Res. 2007;42:1-11.

3. Ikeda Y, Long DM. The molecular basis of brain injury and brain edema: the role of oxygen free radicals. Neurosurgery. 1990;27:1-11.

4. McCall JM, Braughler JM, Hall ED. Lipid peroxidation and the role of oxygen radicals in CNS injury. Acta Anaesthesiol Belg. 1987;38:373-9.

5. Warner DS, Sheng H, Batinić-Haberle I. Oxidants, antioxidants and the ischemic brain. J Exp Biol. 2004;207:3221-31.

6. Hall ED. Lipid antioxidants in acute central nervous system injury. Ann Emerg Med. 1993;22:1022-7.

7. Young IS, Woodside JV. Antioxidants in health and disease. J Clin Pathol. 2001:54:176-86

8. Ghiselli A, Serafini M, Natella F, Scaccini C. Total antioxidant capacity as a tool to assess redox status: critical view and experimental data. Free Radic Biol Med. 2000;29:1106-14.

9. Galley HF. Oxidative stress and mitochondrial dysfunction in sepsis. Br J Anaesth. 2011;107:57-64.

10. Nayak C, Nayak D, Bhat S, Raja A, Rao A. Relationship between neurological outcome and early oxidative changes in erythrocytes in head injury patients. Clin Chem Lab Med. 2007;45:629-33.

11. Kasprzak HA, Woźniak A, Drewa G, Woźniak B. Enhanced lipid peroxidation processes in patients after brain contusion. J Neurotrauma. 2001;18:793-7.

12. Paolin A, Nardin L, Gaetani P, Rodriguez Y, Baena R, Pansarasa O, et al. Oxidative damage after severe head injury and its relationship to neurological outcome. Neurosurgery. 2002;51:949-54.

13. Lorente L, Martín MM, Abreu-González P, Ramos L, Argueso M, Cáceres JJ, et al. Association between serum malondialdehyde levels and mortality in patients with severe brain trauma injury. J Neurotrauma. 2015;32:1-6.

14. Hohl A, Gullo Jda S, Silva CC, Bertotti MM, Felisberto F, Nunes JC, et al. Plasma levels of oxidative stress biomarkers and hospital mortality in severe head injury: a multivariate analysis. J Crit Care. 2012;27:523. e11-9.

15. Kavakli HS, Erel O, Karakayali O, Neselioglu S, Tanriverdi F, Coskun F, et al. Oxidative stress in isolated blunt traumatic brain injury. Sci Res Essays. 2010;5:2832-6.

16. Sögüt O, Kaya H, Gökdemir MT, Solduk L, Dokuzoglu MA, Sayhan MB, et al. Early oxidative status in adult patients with isolated traumatic brain injury. Turk J Med Sci. 2012:42:1010-9.

17. Kaya H, Sögüt O, Gökdemir MT, Albayrak AT. The role of oxidative status in initial evaluation of paediatric patients with graded traumatic brain injury. Hong Kong J Emerg Med. 2013;23:225-33. 
18. Teasdale $G$, Jennett B. Assessement of coma and impaired conciousness A practical scale. Lancet. 1974;2:81-4.

19. Baker SP, O'Neill B, Haddon Jr W, Long WB. The Injury Severity Score: a Method for Describing Patients With Multiple Injuries and Evaluating Emergency Care. J Trauma. 1974;14:187-96.

20. Marshall LF, Marshall SB, Klauber MR, Van Berkum CM, Eisenberg H, Jane JA, et al. The diagnosis of head injury requires a classification based on computed axial tomography. J Neurotrauma. 1992;9:S287-92.

21. Knaus WA, Draper EA, Wagner DP, Zimmerman JE. APACHE II: a severity of disease classification system. Crit Care Med. 1985;13:818-29.

22. Draper HH, Hadley M. Malondialdehyde determination as index of lipid peroxidation. Methods Enzymol. 1990;186:421-31.

23. Dalle-Donne I, Rossi R, Colombo R, Giustarini D, Milzani A. Biomarkers of oxidative damage in human disease. Clin Chem. 2006;52:601-23.

24. Kikugawa K, Kojima T, Yamaki S, Kosugi H. Interpretation of the thiobarbituric acid reactivity of rat liver and brain homogenates in the presence of ferric ion and ethylediaminotetraacetic acid. Anal Biochem. 1992;202:249-55.

25. Chuang CC, Shiesh SC, Chi CH, Tu YF, Hor LI, Shieh CC, et al. Serum total antioxidant capacity reflects severity of illness in patients with severe sepsis. Crit Care. 2006;10:R36.

26. MacKinnon $\mathrm{KL}$, Molnar Z, Lowe D, Watson ID, Shearer E. Measures of total free radical activity in critically ill patients. Clin Biochem. 1999;32:263-8.

27. Lorente L, Martín MM, Almeida T, Abreu-González P, Ferreres J, Solé-Violán J, et al. Association between serum total antioxidant capacity and mortality in severe septic patients. J Crit Care. 2015:30:217. e7-12

28. Farace $\mathrm{E}$, Alves WM. Do women fare worse: a metaanalysis of gender differences in traumatic brain injury outcome. J Neurosurg. 2000:93:539-45.

29. Groswasser Z, Cohen M, Keren O. Female TBI patients recover better than males. Brain Inj. 1998;12:805-8.

30. Hall ED, Vaishnav RA, Mustafa AG. Antioxidant therapies for traumatic brain injury. Neurotherapeutics. 2010;7:51-61.

31. Kerman M, Cirak B, Ozguner MF, Dagtekin A, Sutcu R, Altuntas I, et al. Does melatonin protect or treat brain damage from traumatic oxidative stress? Exp Brain Res. 2005:163:406-10.

32. Horakova L, Onrejickova O, Barchrrata K, Vajdova M. Preventive effect of several antioxidants after oxidative stress on rat brain homogenates. Gen Physiol Biophys. 2000;19:195-205.

33. Ozsüer H, Görgülü A, Kiriş T, Cobanoğlu S. The effects of memantine on lipid peroxidation following closed-head trauma in rats. Neurosurg Rev. 2005;28:143-7.

34. Messenge C, Margail I, Verrechia C, Allix M. Protective effect of melatonin in a model of traumatic brain injury in mice. J Pineal Res. 1998;25:41-6.

\section{Submit your next manuscript to BioMed Central and take full advantage of:}

- Convenient online submission

- Thorough peer review

- No space constraints or color figure charges

- Immediate publication on acceptance

- Inclusion in PubMed, CAS, Scopus and Google Scholar

- Research which is freely available for redistribution 